\title{
POÉTICA DO ESPAÇO GEOGRÁFICO: EM COMEMORAÇÃO AOS 70 ANOS DA AGB.
}

\author{
Dirce Maria Antunes Suertegaray*
}

\section{RESUMO:}

Este artigo constitui na integra a conferência de encerramento realizada pela autora durante o $X$ Congresso da Associação dos Geógrafos Brasileiros e comemoração dos 70 anos da AGB. Resgata do ponto de vista da uma imagem poética, conforme definida por Bachelar, o espaço-tempo de construção da AGB e da Geografia Brasileira durante esse período. Indica as transformações do pensamento geográfico brasileiro e a necessidade de um pensamento conjuntivo na constituição geográfica.Nesse sentido aborda a discussão sempre presente na geografia - a relação sociedade - natureza indicando a necessidade de se avaliar a partir de novas concepções as formas dadas ou a materialidade de espaço geográfico.Aborda essas novas materializações a partir do conceito de híbrido, indicando ao finalizar a necessidade da geografia tecer junto uma série de pares que até então concebe como objetos purificados na medida em que são compreendidos como isolados.

\section{PALAVRAS-CHAVE:}

AGB 70 anos, geografia, espaço geográfico, geógrafos

\section{ABSTRACT:}

This article analyses the concept of peasantry from a socio-cultural approach and supports that it has remained relevant in understanding the Brazilian agrarian reality. This position is due to the conviction that this concept has the capacity to express the complexity of this historic social agent. The paper also supports that peasantry is a social class that has a culture based on a system of practices and representations referring to a traditional order, which has land, work and family as its central values. It explains the use of this concept in the Brazilian social sciences since the fifties and analyses some aspects of the family agriculture that have been employed more and more in place of peasantry. Likewise, this article presents questions about the recreation of peasantry verifiable in the rural settlements according to the analyses of the spatial and social organization of the settlers.

\section{KEY WORDS:}

AGB 70 years, geography, geographic space, geographers

Caros colegas agebeanos. Quero inicialmente agradecer, mesmo sem compreender as razões de estar nesse momento ocupando este lugar. Arlete Moysés Rodrigues possivelmente tenha razão quando se referiu a compressão do tempo. Possivelmente...

Mesmo tendo aceitado o convite, para falar neste final de evento, estou um pouco apreensiva neste lugar. Devo confessar que estou muito tensa e digo isto, pois, aprendi com o educador Paulo Freire, que devemos dizer a quem nos ouve, nossos anseios, nossos medos. Embora revelando esta ansiedade inicial sintome honrada com o convite e desde já agradeço pela distinção. Ao mesmo tempo parabenizo o presidente que hora encerra seu mandato, geógrafo e professor Bernardo Mançano Fernandes e sua diretoria pelo trabalho realizado, árduo trabalho como todos sabemos. 
construíram este congresso, professores, bacharéis e estudantes de Geografia que vindos dos mais diferentes pagos deste Brasil trazem junto consigo as cores, os sabores, os gestos, os movimentos de cada lugar.

Faço também uma referência especial aos homenageados deste evento aos geógrafos: Horiestes Gomes, João de Castro, Roberto Lobato Correia, Paulo Roberto R. Alantejano, Manuel Seabra, Hindemburgo Pires, Arlete Moisés Rodrigues, Beatriz Soares Pontes, Diamantino Pereira.

A homenagem que a AGB lhes presta é de reconhecimento pelo ato continuo de Geografar que de muito realizam.

Para construir esta fala, pensei vários caminhos, cada um deles indicava uma possibilidade, optamos por uma fala leve por isso a intitulei Poética do Espaço Geográfico.

O título, Poética do Espaço Geográfico, foi escolhido ao decidir como falar, neste final de Congresso, inspirada em Bachelar (2000) quando explicita o que seja uma imagem poética dizendo" entendemos pelo (por isso um) estudo do fenômeno da imagem poética quando a imagem surge na consciência como um produto direto do coração,da alma, do ser do homem captado em sua atualidade".(p.9).Optei, portanto, para traçar uma imagem da Geografia, por uma construção livre, baseada sim, na leitura e aprendizado geográfico de 30 anos de profissão, mas não circunscrita aos cânones acadêmicos. Resolvi expressar mais sentimento do que razão (talvez) nesse momento. Esta fala, talvez possa também ser denominada como canta Gonzaguinha "não da mais para segurar, explode coração".

Penso que para projetarmos uma Geografia do futuro, devamos contextualizar o presente. Nosso mundo está carregado de interrogações. Crise tem sido o termo mais usado. De minha parte tenho procurado compreender este momento a partir de um período datado dos anos 70 do século XX. Tratase este para o professor Milton Santos (1994) do período Técnico Científico Informacional. Esta nova fase do capitalismo, reconhecida como Capitalismo Avançado (Harvey, 1993) apresenta-se como crise, na medida em que significativas transformações ocorrem no mundo da produção, no mundo do trabalho, no mundo da cultura e conseqüentemente na subjetividade humana. Este mundo em crise, ou transformação revela uma reordenação e aceleração no processo produtivo decorrente do avanço tecnológico, promovendo desde os anos 60 a emergência da discussão sobre a escassez dos recursos, a degradação da natureza, enfim a questão ambiental. Neste, ao mesmo tempo, que se impõem novas formas de organização do trabalho que exclui uma grande contingente de trabalhadores, promove-se o sobre trabalho para os poucos trabalhadores em atividade formal e remunerada. Além da exclusão o mundo do trabalho desregulamenta e terceiriza. O que significa o fim da estabilidade e quiçá a negação da possibilidade de pensar o futuro.

Estamos à mercê de uma nova construção social que sustentada sobre a necessidade crescente de acumulação do capital nos encaminha a repensar as categorias fundamentais que dão suporte a formulação do espaço geográfico, natureza, sociedade, espaço e tempo e ao mesmo tempo exige que pensemos sobre qual ou quais as geografias se constroem neste momento de grandes incertezas, mas, também, de grandes possibilidades.

Cabe refletir então sobre geografia e sobre o fazer geográfico.

Para exemplificar esta fala tomo como referência o texto/discurso das últimas formaturas da Geografia do ano de 2003, na UFRGS. Penso que as idéias lá expostas dizem respeito ao que aqui desejo colocar.

Tomo como referência a célebre frase resgatada por Fernando Pessoa e proveniente dos navegadores da antigüidade.

"Navegar é preciso, viver não é preciso". Resgato esta frase para, ao trazê-la para a contemporaneidade, dizer que é possível parafrasear o poeta de outra forma, dizendo: 
Geografar é preciso, viver não é preciso.

Geografar é preciso pois, frente à realidade do mundo atual não só as ações de analisar e interpretar os espaços de vida são necessários. É preciso ir além, e isto significa Geografar - deixar marcas, criar espaços, transformar espaços de vida, mudar pela intervenção compartida a formaconteúdo que desqualifica o viver humano por uma outra forma-conteúdo que qualifique este viver. Esta tem sido a tarefa historicamente posta para a Geografia, campo de conhecimento e ação que escolhemos para exercer nossas atividades profissionais. Muitas vezes, ao longo da história, a Geografia foi condenada por ter ficado atrelada aos grandes senhores e aos poderes.

A tarefa mais recente da Geografia é geografar, na perspectiva da mudança social, da transformação de um mundo onde o cidadão é um mero consumidor para um mundo, onde o processo de construção da cidadania seja condição de um geografar coletivo. Geografar, portanto, não é só uma tarefa de geógrafos, é uma tarefa ampla que necessita ser espraiada no corpo social. Este espraiamento é, sem dúvida, parte de nossa tarefa enquanto profissionais da Geografia, sejamos nós, professores ou bacharéis. É tarefa da nossa associação a partir de nós.

Geografar é preciso! Viver não é preciso! Na fase atual da História podemos interpretar que: viver não é preciso porque é incerto. A incerteza é hoje o princípio que rege o processo de conhecimento do mundo. Este se torna cada vez mais evidente, pois não há precisão ao viver, a vida é incerta. E, a ciência interpreta a vida. Esta incerteza todos nós a vivemos. No mundo moderno, a aceleração do tempo através do advento de novas tecnologias associadas ao processo de reestruturação produtiva promove transformações no mundo do trabalho em escala mundial, promove mudanças rápidas em nosso cotidiano não nos permitindo projetos de longo tempo. Não nos permitindo estabilidade, não nos permitindo garantia de direitos já adquiridos. Esta nova fase exige cada vez mais produtividade, competência e concorrência.

Quero também resgatar, nesta fala,
Saramago, para, através da interpretação do cosmos realizada por ele alertar sobra à incerteza, sob outra perspectiva. Em seu discurso quando recebeu o título de Honoris Causa na Universidade Federal do Rio Grande do Sul dizia: "Deus, quando criou o universo, aquilo que tinha em mente era entregá-lo todo à sua outra magna criação, isto é, o Homem. Realmente não teria sentido criar uma coisa tão grande... para depois pôr o ser humano, sua criação mais perfeita, pois que o criara a sua imagem e semelhança, a viver num minúsculo planeta de uma galáxia secundaríssima. Reconhecemos que não era isto que poderia esperar-se de um Deus. Portanto, o lógico e o óbvio era começarmos por habitar o universo inteiro. Quanto tempo durou isto não sei nem posso saber. O certo foi ter percebido Deus que estávamos a dar-Ihe cabo do que tanto trabalho Ihe tinha custado e, ainda por cima, sabendo Ele que não poderia fazer outro universo, uma vez que este ocupa o espaço todo. Então que fez Deus? Agarrou naqueles antepassados nossos, em todos eles e trouxe-os para aqui dizendo: "já que vocês gostam de destruir, então que seja um planeta de cada vez, e não o universo inteiro". A visão do literata nos remete a Morin (2002), na medida em que indica a incerteza do viver planetário, também sob a ótica ambiental e, na medida em que sugere que devemos ensinar a identidade terrena buscando decifrar a "era planetária" com todas suas heranças, conflitos, medos, esperanças e possibilidades". Suertegaray, trechos dos discursos para os formandos de 2003/1.

Diante da incerteza, da crise e da possibilidade/necessidade de mudanças cabe nos perguntar nesse momento, sobre geografia e sobre a nossa Associação a AGB (Associação dos Geógrafos Brasileiros) que neste Congresso comemora seus 70 anos.Penso que é tarefa dos geógrafos e por extensão da AGB : Geografar.

"Podemos como a Geografia ensina ter uma atitude passiva, contemplativa e descritiva do mundo, podemos como ela também nos ensina, ter uma atitude ativa no mundo. Geografar, portanto, pode ser descrever a terra, mas muito mais do que isto, geografar no mundo atual significa grafar a Terra. Grafar no sentido de deixar 
um registro, demarcar, marcar, territorializar, ambientalizar, regionalizar, enfim, como nos fala o colega Nélson Rego (2000) gerar ambiências, ou seja, espaços de convívio solidário e justo, espaços de inclusão social... Estas geografias são seguramente praticadas, por nós geógrafos, a partir do lugar que ocupamos profissionalmente, constituem centelhas no movimento do mundo, mas se organizadas em rede poderão expandir-se num fazer solidário. Esta geografia não se encontra em livros embora possa ser registrada através deles. Constitui-se em formas de agir no movimento da sociedade, em construções criativas que abram caminho profissional e social. Digo isto posto que na atual conjuntura geografar é preciso, o mundo se modifica aceleradamente, portas se fecham, portas se abrem. Cabe ao geógrafo construir possibilidades e, novas possibilidades, só poderão vir do ato de Geografar.

Geografar,constitui uma atividade inerente à nossa ação cotidiana é a expressão do que somos em qualquer lugar onde estamos. Implica promover ações cotidianas com responsabilidade social sobre nossos atos, nossas práticas, nossa atividade profissional. Implica em experiência participativa e vivência coletiva, com responsabilidade para com os outros e a sociedade em seu conjunto.

Constituem essas práticas formas de Geografar, formas de demarcar, marcar, territorializar, ambientalizar, regionalizar o espaço. Formas de resistir e transformar. "Trecho do discurso proferido aos formandos 2003/2

Os geógrafos tenham eles, optado por serem bacharéis e/ou licenciados, têm demonstrado e deixado registrado este fazer.

Geografaram os geógrafos brasileiros de forma associativa desde a fundação da AGB. Naquele tempo dado as necessidades demandadas daquele momento histórico e desenvolvimento tecnológico geografaram palmilhando o território nacional, através de excursões e registros de campo presentes em nossa memória e em nossos arquivos Agebeanos. Um dos exemplos constitui a Exposição sobre o geografar de Caio Prado
Junior, um dos fundadores da AGB, trazido em forma de exposição para este evento.

Construíram um conhecimento sobre o território e indicaram caminhos de ordenação/ regionalização do espaço brasileiro. Geografaram a partir das necessidades do Estado de reconhecer o território na "marcha para o oeste",como nos ensina o professor Carlos Augusto Figueiredo Monteiro (1981) ao se referir ao período Vargas e a criação do IBGE.Também geografaram ao fornecer subsídios à regionalização no período ditatorial. Trata-se, como dizíamos de deixar marcas, marcas que nesse período, como também em outros de sua história vincularam a geografia ao Poder, por conseguinte severas críticas lhes foram, posteriormente outorgadas.

Geografaram nos anos 70 no âmbito de um movimento de renovação que promoveu significativas mudanças na organização dos geógrafos em sua associação.Promoveu significativas mudanças no fazer geográfico e nas ações demandadas. Há esse tempo, com o retorno há formas de administrar mais democráticas associadas a um mundo em crise, ampliam-se às demandas sociais. Estas decorrem de mudanças significativas no modo de viver dos brasileiros com a ampliação do processo migratório e crescimento das cidades, do aprofundamento da crise social, decorrente da diminuição dos postos de trabalho, da ampliação do processo produtivo no campo associado à agricultura comercial, hoje denominada de agronegócio e, da questão ambiental como decorrente das formas de uso e apropriação da natureza sob a lógica capitalista.

Geografaram os geógrafos na medida em que se engajaram nas demandas sociais mais amplas provenientes dos movimentos sociais e de suas reinvindicações ou geografaram expressando suas leituras sobre a ambiente no contexto da sociedade em que vivemos. Geografaram ao colocar questões relevantes sobre a contradição presente entre 
a vida precária e a vida exuberante dos brasileiros.

Geografar a partir desses anos, considerando que de lá para cá mais complexo e contraditório é o mundo em que vivemos, constitui ocupar um lugar e buscar, enquanto, possibilidade de vivência responsável, a solidariedade (com os outros) o cuidado (com os objetos) a responsabilidade ética (com as ações). Mais amplamente Geografar pode significar viver uma vida biográfica, tendo consciência de que somos seres históricos e geográficos, portanto, capazes de participar das mudanças no mundo, demarcando materializando no espaço ações coletivas de maior justiça social.

Uma geografia da ação não demanda, entretanto, da pura experiência ou das facilidades tecnológicas atuais. Uma geografia da ação exige uma base conceitual forte que, ao mesmo tempo, amplie a concepção do mundo e indique a possibilidade de construção de estratégias de ação. Nesta perspectiva cabe levantar algumas questões que considero importantes para pensarmos o espaço geográfico, nosso conceito balizador.

Para tanto, pensemos um pouco sobre as renovações no mundo do conhecimento onde a Geografia como campo específico se insere.

A ciência tem desde as últimas décadas do século passado indicado a necessidade de mudanças na forma de construir o conhecimento. Estas dizem respeito não só a construção conceitual, mas também de metodológicas e de procedimentos, considerando que as mudanças do mundo exigem novas formas de concebê-lo. Algumas dessas discussões dizem respeito direto a Geografia.

Lembremos para iniciar esta abordagem que a Geografia ao se constituir autonomamente (na modernidade) colocou-se como ciência de interface entre natureza e sociedade. Lembremos que neste momento histórico a construção do conhecimento era sustentada pela doutrina positivista, que entre outras questões separa natureza e sociedade como campos distintos do conhecimento. Lembremos que ao longo do século $X X$ a Geografia mais se fragmentou que promoveu a conexão um de seus princípios desde os clássicos.

Entretanto, a quebra dos paradigmas clássicos, a necessidade de conjunção científica e a compreensão da complexidade (Morin 1990) permite à Geografia novas possibilidades, na medida em que para este mesmo autor é a Geografia uma ciência do complexo. Complexidade é aqui entendida conforme Morin como - complexus (o que é tecido junto), conjugação, conexões...

Assim, mesmo que nossa experiência seja em grande medida de separação/ disjunção, paradoxalmente, somos aqueles que, historicamente buscamos a conjunção (natureza/sociedade ou natureza/cultura ou, em termos escalares global/regional/local), portanto, trata-se de um campo privilegiado e de um conteúdo necessário na atualidade.

Sob estes novos ventos coloca-se para a Geografia novas questões. A idéia de construir conhecimento conjuntivo resulta do desenvolvimento do próprio mundo e nele à ciência. A esse respeito sabemos que a questão ambiental, que num dado momento de nossas discussões foi reconhecida como contradição secundária, frente à contradição principal que move nossa sociedade (capital / trabalho),emerge na atualidade como questão fundamental, promovendo inclusive novas construções científicas a exemplo da: Ecologia Profunda; que ao pensar a relação natureza sociedade privilegia a preservação da natureza indicando a culpabilidade do homem ou da sociedade, na sua totalidade, em relação a sua degradação; a Economia Ambiental; que através de raciocínios eminentemente econômicos sugere a internalização da natureza mediante a sua valoração no âmbito do processo produtivo ou o Ecodesenvolvimento ou a Epistemologia Ambiental de Leff (2001) que indica a necessidade de preservação eqüitativa 
da natureza e da cultura nas suas diferentes formas organização social. De maneira diferente, dado que refletem visões de mundo politicamente diferenciadas, estas tendências têm em comum a necessidade de pensar conjuntamente: natureza e sociedade. E ainda mais refletir sobre o próprio conceito de natureza.

Cabe aqui um longo parêntese para resgatar a concepção de natureza entre os geógrafos clássicos, particularmente, Reclus.

Os Anarquistas partem do princípio de que a natureza é harmoniosa, organizada a partir de uma ordem material. Esta natureza harmônica é regida por leis que o homem não pode transgredir. Estas são as únicas leis que os anarquistas admitem. O conhecimento destas leis é a condição necessária para a liberdade humana. Fazer geografia física é, portanto, fazer o estudo da harmonia terrestre.

Hoje é claro o avanço do conhecimento científico indica, ao contrário do romantismo da época, que a natureza não é necessariamente harmônica. Mas, sobretudo, no âmbito da ecologia profunda esta idéia parece prevalecer.

Sob esta construção, segundo Giblin (1998), os geógrafos anarquistas são os primeiros ecologistas, na medida em que consideram que a terra é um planeta vivo, onde as ações humanas com seus efeitos negativos e / ou positivos demandam do sistema político e econômico a que estão ligados. Reclus considerava que:

"Elle peut embellir la terre, mais elle peut aussi I'enlaidir; suivant I' 'etat social et les moeurs de chaque peupel, elle contribue tantôt à degrader la nature, tantôt à la transfigurer (Reclus, La terre, tomo II, p748).

A geografia e por extensão 0 conhecimento da natureza é um saber útil ao anarquismo e o conhecimento geográfico confirma profundamente as teorias libertárias.

Uma organização anarquista da sociedade se orienta a partir da organização natural do mundo. O meio geográfico se caracteriza pela organização bem individualizada de pequenas regiões geográficas e que seria em função desse quadro que deveriam se organizar as comunas (comunidades). Considera que a divisão política entre os estados e anti - natural.

Perguntam - se hoje alguns intelectuais estaremos resgatando ou nos apropriando hoje de parte desse discurso, em particular naquilo que interessa as grandes corporações quando falamos de autogestão e descentralização.

Reclus considera que a Geografia dá significativa importância aos problemas espaciais quer sejam regionais, nacionais ou internacionais. Ao contrário Marx teria dado pouca importância ao espaço.

Reclus se contrapõe ao determinismo geográfico, para ele o meio físico não comanda, não determina as organizações econômicas e sociais dos grupos humanos, sob condições naturais comparáveis (semelhantes) se constroem organizações econômicas e sociais fortemente diferentes. A interação do homem com o meio(a natureza) é diversificada, podendo ser sadia ou patológica.

Considera que o meio(a natureza) é dinâmico e, portanto, só o conhecimento desta dinâmica permite uma boa utilização e exploração do conjunto natural. Admite que a interferência humana em um de seus elementos promove automaticamente uma mudança nessa dinâmica criando um novo equilíbrio ou desequilíbrio. Dá importância ao conhecimento dos fenômenos terrestres e do meio natural.

Reclus conduz sua análise articulando estreitamente o espaço e o tempo.

Para ele "La géographie n'est outre chose que I'histoirie dans l'espace, de même que I'histoire est la geografhie dans le temps" L' homme et la Terre)".

A valorização da história no processo de transformação social em Marx teria, de acordo com algumas análises, encaminhado os 
geógrafos marxistas a negligenciar o espaço e conceber a natureza como recurso a ser apropriado, distintamente, no decorrer da história de construção social. Por conseqüência o conhecimento da natureza, reconhecido entre os geógrafos como geografia física, foi por parte destes, desconsiderada na análise geográfica.

Presenciamos este debate desde o advento da Geografia Crítica, presenciamos as mais severas críticas sobre a compreensão da dinâmica da natureza no contexto da abordagem geográfica no Brasil. Devemos considerar, entretanto, que Marx não desconheceu a natureza, o que fez foi indicar que esse conhecimento específico se fazia no âmbito da história natural. Enquanto a história dos homens deveria ser feita a partir da compreensão do processo de socialização do homem e neste e com este a socialização da natureza.

Se nós, denominados geógrafos físicos, na época tivéssemos utilizado da obra de Reclus poderíamos ter tido uma inclusão, nesse debate, com maior força argumentativa.

Interessa, portanto, a Geografia essa discussão na medida em que ela remete a um debate tão presente entre nós.

Entretanto, neste momento histórico, novas dimensões se interpõem. Na atualidade a necessidade de conjunção do conhecimento deriva do reconhecimento de que o processo de apropriação da natureza, ao longo da história do homem resultou num progressivo processo de apropriação, domesticação, manipulação e hoje reprodução, tornando o que entendíamos como natural um híbrido ou progressivamente híbrido como nos ensina Latour (1994) e como também se referiu Milton Santos(1996).

Os híbridos para este autor fazem parte de nossa construção histórica, para ele a ciência moderna ao promover a separação dos objetos no desejo de explicá-los na sua pureza, simplificou - os, descontextualizou - os. Por essa razão para Latour (1994) - Jamais fomos modernos - nosso entendimento de mundo mostra um descompasso entre ciência e esse mesmo mundo e, este descompasso se revela nas crises mais contemporâneas.

Refletindo a partir de Latour (1994) concluo que a Geografia, também, jamais foi moderna, na medida em que sustentou a necessidade de articulação entre natureza e sociedade num contexto histórico de separação e purificação dos objetos.

Esta discussão nos remete a reflexão no campo da tão debatida Geografia Física e neste contexto à concepção de natureza. Muitos de nós geógrafos, amparados na filosofia, já indicaram que o conceito de natureza é uma construção social, que a separação advém de uma necessidade de conhecer a natureza para dominá-la e que entendida como externalidade constitui suporte ao desenvolvimento das forças produtivas.

Devemos ter presente que a concepção de natureza em sendo um produto das culturas é histórica e espacialmente distinta, portanto, mesmo hoje, a despeito do processo de globalização econômica vivemos concepções diferenciadas, pois constituímos um mundo de significativa diversidade cultural.

Mas, nós particularmente, fazemos parte da cultura ocidental, que construiu a idéia de separação da natureza ou a idéia de natureza externalizada.

Este debate está posto hoje aos Geógrafos. Milton Santos (1996) já nos indicou que a natureza é hoje artificializada enquanto - professor Carlos Augusto de Figueiredo Monteiro (2003) nos fala de derivações e eu tenho falado de transfigurações. Em ambos os casos Santos e Monteiro nos indicam transformação, reprodução.

Ao atentarmos para nossas práticas veremos que grande parte do conhecimento da natureza feita hoje se articula com a dinâmica social na busca da explicação dos impactos ambientais. Refletindo sobre nossa atividade tenho compreendido e neste sentido 
acompanho as idéias de Milton Santos. Em meu entendimento sob qualquer perspectiva, hoje, tratamos de natureza artificializada. Sob qualquer perspectiva, desde os diagnósticos, passando pelos monitoramentos e indicação de medidas mitigadoras, quando das análises ambientais estamos trabalhando a partir de uma artificialização. Está é expressão do nosso tempo.Resulta, portanto, necessário assumirmos esta discussão. Penso que neste momento histórico dado a capacidade técnicocientífica de reprodução da natureza à Geografia não caberia tão somente o estudo da relação sociedade/ natureza posto que estas se configuram amalgamadas, híbridas e sob alguns aspectos dependentes reciprocamente. A título de exemplo, hoje sabemos que o milho não se reproduziria sem a presença do homem, da mesma forma as ovelhas se não fosse o manejo estariam extintas, assim dizem os agrônomos e veterinários. Ou sob outra perspectiva, a da imagem, não seriamos tão belos e jovens como procuramos ser via exercícios em aparelhos ou através do uso do silicone. Nós próprios, reconhecidos pela biologia como seres naturais, hoje, já não somos puros como a modernidade quis indicar, da mesma forma as paisagens, as regiões os lugares.

Tempo e espaço também nos convidam a uma reflexão, o período atual dado o desenvolvimento fantástico de novas tecnologias indicam como muitos já fazem uma reflexão sobre tempo e espaço. A modernidade privilegiou a idéia de tempo longo, tempo histórico, fé no futuro e com ele a possibilidade de desenvolvimento. 0 presente se ampara na destruição da idéia de tempo longo, assumindo a perspectiva do presentismo, do imediato, do fugaz. Ao mesmo tempo revela a possibilidade de pensar o tempo não linear favorecendo a construção da simultaneidade do tempo, dos ritmos sejam da natureza sejam da sociedade, favorecendo a construção da concepção de temporalidade como simultaneidade tempo espaço.

A contemporaneidade permite também, como bem expressou Prigogine (1996), indicar que não há reversibidade do tempo, o que ocorre são bifurcações, portanto, possibilidades.

Afetam o pensamento geográfico, necessariamente essas construções. Se nos associarmos ao puro presentismo podemos estar valorizando o espaço, na medida que o que vale é o aqui (lugar) e o agora.Sem projeção para o futuro podemos cair na rede da contemplação do mundo, da explicação da funcionalidade ahistórica e do conformismo. Se nos associarmos à idéia de não reversibilidade e simultaneidade podemos revelar o passado no presente e projetar novas possibilidades, novos futuros.

Neste contexto de transformações as tecnologias de análise espacial se expandem consideravelmente, o que pode nos revelar tal avanço. Entre outras coisas, como geógrafos, devemos refletir sobre estes usos.Temos com elas possibilidades de produção de análises espaciais rápidas, elas nos beneficiam, e ao mesmo tempo nos aprisionam numa dinâmica de resultados em tempos curtos e respostas rápidas. Soluções momentâneas, passageiras e brevemente superadas, indicando a emergência do espaço sem história, dado que ressaltam a forma e em menor escala a funcionalidade.

A sociedade, categoria fundamental na análise do espaço geográfico se diversifica, também nessa contemporaneidade, em sociedades - culturas, indicando que se de um lado o caminho da economia, nos sugere globalização à perspectiva da resistência nós encaminha a compreensão das culturas.

A perspectiva de compreender o diferente e sua identidade interna rompe com perspectivas da Geografia que, há um tempo muito próximo, nos falavam da necessidade de produzir modelos e ou leis de explicação do espaço geográfico. Não há como compreender as diferenças através de métodos comparativos e generalizadores.Paradoxalmente, retorna-se aos clássicos, a exemplo de La Blache, Sauer, Reclus entre outros para captar a forma de construir a explicação da diferença. 
Reconstruímo-nos, conforme já expôs o prof. Carlos Augusto Monteiro em muitas de suas falas, através de uma espiral ascendente, onde o retorno aos clássicos se faz necessário para prosseguir, certamente, de outra maneira, a perseguir o futuro.

Neste contexto tão complexo e diversificado perseguir caminhos de interpretações geográficas parece ser mais apropriado do que pensar em objeto geográfico. As construções científicas contemporâneas também romperam com a possibilidade de um único método indicando a possibilidade das múltiplas interpretações. No âmbito dessa reflexão nos aventuramos, há um tempo atrás, numa teorização sobre Geografia.

Construí a partir dessa reflexão a idéia de que o espaço geográfico é uno múltiplo e constitui nosso conceito balizador. Agora operar sobre o espaço geográfico demanda trabalharmos com o que denominei de conceitos operacionais a exemplo dos conceitos de paisagem, região, território, lugar, redes e também ambiente.

Estes conceitos, em meu entendimento permitem que façamos uma leitura diferenciada do espaço geográfico, na medida em que, cada um deles privilegia uma dimensão da multiplicidade espacial: paisagem; conjunção de fatores físicos ou físicos e sociais, região; espaços de homogenidade, funcionalidade ou identidade espacial, identificados pela economia ou pela cultura, território; apropriação e dominação, portanto poder, lugar; percepção/ representação da existência subjetiva ou intersubjetiva (intermundos), redes; fluxos expressos em nós em conexão e finalmente ambiente a compreensão do ser na relação com seu entorno e a expressão das transformações/ derivações/ transfigurações em um e em outro...Todas essas dimensões fazem parte da complexidade e no espaço geográfico estão tecidas juntas. Frente à dificuldade da compreensão da totalidade a partir de um único sujeito cada geógrafo ao escolher um ou mais conceitos opera com uma ou mais dimensões.
Mesmo sabendo que todas estão amalgamadas dado que espaço geográfico contém paisagens, territórios, regiões, lugares, redes e ambientes que se desvelam dependendo do caminho escolhido para sua interpretação.

Esta constitui em meu entendimento a nossa riqueza a unidade na diferença.

Não obstante sabemos e queremos deixar aqui registrado que esta é uma interpretação, outros caminhos são trilhados todos eles são indicativos de possibilidades diversas frente ao mundo em que vivemos.

Quero dizer com esta longa fala que particularmente considero que estamos num momento privilegiado para a Geografia, o temário geográfico está na pauta da discussão contemporânea desde o ambiental, ao econômico, ao poder e o cultural passando pelos espaços da subjetividade e da Ecosofia (Guatari, 1991). Os temas decorrem da complexidade e das respostas que devemos construir aos problemas contemporâneos por isso vislumbram-se trabalhos no âmbito ambiental como os diagnósticos ambientais, no âmbito das identidades regionais, das estratégias de regionalização, na revitalização assim como na regularização urbana, nas transformações do espaço agrário (agronegócio) e os movimentos pela terra, no contexto do mundo do trabalho, a exclusão, o trabalho informal, a moradia, a qualidade de vida,da saúde, a fome, a violência, a preservação, o turismo, a defesa das populações tradicionais bem como a religiosidade, a cultura, as diferenças, o gênero além do ensino...Como bem demonstraram as mesas redondas, cursos, comissões coordenadas e espaços de diálogos desse Congresso. Nossa diversidade é, portanto, nossa matriz.

Quero ainda fazer uma menção que considero importante, trata-se do ensino da Geografia, se observarmos com atenção, o ensino da Geografia que, nos anos 70/80 sofreu severas críticas, transformou-se e transformase seja nos livros ou nas propostas de ensino. Os geógrafos educadores têm dado uma 
contribuição significativa nessa construção. Embora esta mudança possa parecer pequena, para quem acompanha esse debate ela se reveste de grandes inovações, hoje não só pensamos o ensino formal, pensamos também o ensino que inclua grupos sociais outrora excluídos, grupos outrora considerados deficientes, a exemplos dos cegos e dos surdos. Avança a busca de inserção destes na sociedade através do conhecimento e das práticas geográficas formais e informais. Avança com a cartografia geográfica à eles destinada entre tantos outros instrumentais de ensino.

Muito é preciso fazer pela educação nesse país, por isso lembrar da atividade profissional dos professores que espraiados pela imensidão desse território fazem da Geografia um ensino de resgate do ser humano é fundamentalmente importante neste final de Congresso.

Enfim fui solicitada a indicar as possibilidades da Geografia, ou seja, tentar visualizar o futuro. Penso ser esta uma tarefa muito complexa, por isso frente ao que disse apenas me arriscaria indicar que os novos paradigmas em debate indicam para a ciência e neste contexto particularmente à Geografia a necessidade de tecer junto:

Natureza/sociedade

Natureza/cultura

Tempo/espaço

Teoria/prática

Técnica/poesia

Conhecimento/ação

Bacharelado/licenciatura

Ensino/pesquisa

Ensinar/aprender

Geografia Física/ Geografia Humana

Cidade/campo

Local/global/ mundial

\section{Lugar/mundo}

Enfim: Terra/mundo.

E, por que não lembrar, em relação a AGB da necessidade de tecer junto as locais e a nacional. Comumente enfrentamos está questão a identidade da AGB. Trata-se de movimento ou de organização? Pela minha vivência acredito que é também necessário tecer junto movimento e organização encaminhando um estatuto que, ao mesmo tempo em que de organicidade a AGB permita a tão desejada autonomia.E mais, que este tecer junto promova uma identidade que assimile que as locais são a nacional dado que esta, como diretoria, não poderá estar em todos os locais.

$\mathrm{E}$ que possamos entender que quando falamos de maior visibilidade da AGB estamos nos referindo na maioria das vezes à sua atuação em escala nacional.

Esta constitui tarefa difícil frente a nossa organização, entretanto, nosso momento atual, nos permite via novas tecnologias construirmos (o que já vem sendo feito) uma rede, muitas redes, que agrupem geógrafos sobre os mais diferentes temas e que na hora do embate possamos estar munidos de teses a ser defendida em cada local e desta forma nos re alimentarmos para geografar.

Para finalizar, quero homenagear todos os sócios da AGB desde sua criação (em 17 de setembro de 1934) até hoje. Esta associação foi construída a partir do trabalho de cada um ao longo desses anos, 70 anos. Constitui compromisso das gerações presentes e futuras a continuidade deste processo. A AGB é de fato à associação dos geógrafos brasileiros, estejam eles presentes ou ausentes. Pois ninguém nega sua história e sua resistência. Acaba-se de uma ou de outra forma sendo identificado com ela.

Seu futuro, desejo que seja profícuo, que continue nos acolhendo e que cada vez mais amplie sua organização e movimento. Que ao nos acolher/acolhermos repeite/repeitemos nossas diferenças. 
Inspirada na visão de Reclus, o que desejo é uma AGB que fortaleça a ajuda / respeito mútuo e a solidariedade, embora esta possa ser, como se referia Milton Santos(1996), uma solidariedade funcional posto que é, na essência, contraditória e conflituosa. Desejo que permaneça marcando sua presença na discussão/debate da realidade brasileira, geografando possibilidades de mudanças referenciadas em seus vários espaços - tempos daqui para frente, como vimos realizando desde 1937, alimentados pelo sonho de seus idealizadores e hoje espraiada através das seções locais por grandes parcelas do território brasileiro. Consolidá-la ainda faz parte de nossa construção. Obrigada.

\section{Bibliografia}

BACHELARD, G.La Poética del Espácio. Fondo de Cultura Económica. México, 2000, p.281.

CARVALHAL,T.F.(org) Saramago na Universidade. Porto Alegre. Editora da Universidade/UFRGS. 1999.

GUATTARI, F. As Três Ecologias. Papirus Editora, $3^{a}$ Edição. Campinas, 1991.

HARVEY , D . , Condição Pós - Moderna . Editora Loiola , 2 Edição São Paulo, 1993.

LATOUR, B. Jamais fomos Modernos. Tradução de Carlos Irineu da Costa Editora 34, Rio de Janeiro, 1994.

LEFF, H. .Epistemologia Ambiental.Editora Cortez.São Paulo 2001.

MARX E ENGELS.A Ideologia Alemã. (I Feuerbach). São Paulo. Editora Grijaldo,Idta.1977.

MORIN, E. Os Sete Saberes necessários à Educação do Futuro. $2^{a}$ Edição. São Paulo:Cortez.Brasília, DF: Unesco 2000.

MORIN, E. A cabeça bem - feita: repensar a reforma o pensamento. 7a Edição. Rio de Janeiro. Bertand Brasil, 2002.p.128.
MONTEIRO, C.A.F. A Geografia no Brasil (19341977) São Paulo. Instituto de Geografia. USP. Série teses e Monografias, no 42. 1981.p.133

PRIGOGINE, I. O Fim da Certezas. Ed. da Universidade UNESP. São Paulo, 1996.

RECLUS, E . L' homme et la Terre / introduction et chiox des textes Béatrice Giblin. Reéd - Paris : La Dé couverte, ( La Découvert / Puche ; 48. Sciences humaines et Sociotes. 1998.

REGO , N. ; SUERTEGARAY, D. M. A. ; HEIDRICH, Á. (org.). Geografia e Educação Geração de Ambiências . Editora da Universidade UFRGS, Porto Alegre, 2000.

SANTOS, M. Técnica Espaço. Tempo. Globalização Meio Técnico- Científico informacional. Editora Hucitec. São Paulo, 1994.

SANTOS, M. A Natureza do Espaço : Técnica e Tempo Razão e Emoção . Ed. Hucitec, São Paulo, 1996.

SUERTEGARAY, D. Espaço Geográfico Uno Múltiplo In.SUERTEGARAY . D . M. A.; BASSO, L. A. , VERDUM, R. (orgs.) Ambiente e Lugar no Urbano. A Grande Porto Alegre. Editora da Universidade UFRGS, Porto Alegre, 2000.

Trabalho enviado em maio de 2005

Trabalho aceito em setembro de 2005 
